\title{
THE SYSTEM LIQUID IRON-CARBON OXIDES
}

\author{
By H. C. Vacher
}

ABSTRACT

The value 0.0025 previously obtained for the product of the carbon and oxygen contents of liquid iron under specified conditions has been confirmed. The method of approaching equilibrium consisted of passing a known mixture of carbon oxides at one atmosphere pressure over liquid iron maintained at $1,580^{\circ} \mathrm{C}$. After approximately 90 minutes the liquid iron was allowed to freeze in the crucible and the ingot was analyzed for carbon and oxygen. Equilibrium was approached from both directions by adjusting the composition of the charges.

Additional experiments on the system liquid iron-hydrogen-water vapor showed that the data of both systems were in good agreement with data for the water-gas reaction.

\section{CONTENTS}

I. Introduction

Page

II. Experimental Procedure

1. The System Liquid Iron-Carbon Oxides

2. The System Liquid Iron-Hydrogen-Water Vapor

3. Discussion........

III. Summary

\section{INTRODUCTION}

In a previous paper ${ }^{1}$ it was shown that the product of the concentrations of carbon and oxygen, for a number of ingots representing liquid iron at $1,620^{\circ} \mathrm{C}$. and in contact with carbon oxides, was a constant within the limits of experimental error for a single ingot. The average value of the carbon-oxygen products obtained was 0.0025 , which is approximately twenty times larger than the only other direct experimental value. ${ }^{2}$ However, the value 0.0025 agrees with values ${ }^{3}$ obtained from samples of basic open-hearth steels taken during the process of refining when the rate of carbon elimination was small. This agreement was not sufficient to determine the accuracy of the value 0.0025 , and experimental work has been continued. The work was extended to include a few experiments on the system liquid iron-hydrogen-water vapor in order that the accuracy of the data obtained could be judged by correlation with related equilibria.

\section{EXPERIMENTAL PROCEDURE}

The method of attaining equilibrium consisted of passing a known mixture of carbon oxides, at one atmosphere pressure, over liquid iron maintained at a temperature of $1,580^{\circ} \mathrm{C}$. After approximately 90

\footnotetext{
1 H. C. Vacher and E. H. Hamilton, Carbon-oxygen equilibrium in liquid iron. Trans. Am. Inst. of Mining \& Metallurgical Engrs., vol. 95, pp. 124-140, 1931.

2 A. B. Kinzel and J. J. Egan, Experimental data on the equilibrium of the system iron-oxide-carbon in molten iron. Trans. A.I.M.M.E., Iron and Steel Division, pp. 300-319, 1929.

3 C. H. Herty, Jr., Discussion. Iron and Steel Technology, A.I.M.M.E., p. 131, 1928.
} 
minutes' exposure to the gases, the liquid iron was allowed to solidify in the crucible and the resulting ingot was analyzed for carbon and oxygen.

The furance arrangement was essentially the same as used in the previous work. ${ }^{4} \quad$ A magnesia crucible containing the iron was placed in a round-bottom alundum thimble which rested on a magnesia block containing a rounded depression. This facilitated centering the crucible and bringing the top surface of the charge in line with the guide tube and the eyepiece of the furnace top. The temperature was measured by means of an optical pyrometer of the disappearing filament type. The pyrometer was calibrated under black-body conditions to \pm 10 degrees. As the temperature readings during an experimental run were made on the surface of the liquid iron it was necessary to correct the temperature corresponding to the calibration for emissivity. Black-body conditions necessary for the determination of this correction were obtained by means of a crucible that contained a 3 millimeter bore tube centered to coincide with the lognitudinal axis of the crucible. The length of the tube which was heated by the charge was 22 or more millimeters. In order that the bottom of the hole would be at the temperature of the charge the tube was filled with magnesia sand to a depth of 7 millimeters above the bottom of the crucible. The emissivity correction was determined by taking alternate readings in the sight tube and on the surface of the liquid iron. With this furnace arrangement, pyrometer readings are reproducible within 2 milliamperes or 15 degrees.

Each mixture of carbon monoxide and carbon dioxide used was prepared by passing carbon dioxide, from a cylinder, through crushed graphite which was held at a predetermined temperature. The amount of carbon dioxide in the mixture of carbon oxides was controlled by varying the temperature of the graphite, for example, if the graphite was maintained at $1,050^{\circ} \mathrm{C}$., the resultant gas mixture contained about 11 percent carbon dioxide. Lower temperatures increased and higher temperatures decreased the carbon dioxide content. For a given temperature, the composition of the mixture could be varied to some extent by modifying the rate of flow of gas through the hot graphite. Analyses of several samples showed that the prepared mixtures contained not less than 99 percent carbon oxides, with about 0.3 percent nitrogen and 0.7 percent hydrogen as impurities. The gas mixture was stored over a saturated brine solution and the hydrostatic pressure of the displaced solution. was employed to force the gas through drying towers and through the furnace in a subsequent experimental run. Hydrostatic pressure equivalent to 2 or $3 \mathrm{~cm}$ of mercury was sufficient to maintain a steady flow of gas through the furnace.

It was found that the carbon dioxide content of a reservoir full of mixed gases decreased steadily as the reservoir was emptied, presumably on account of the selective solubility of carbon dioxide in the brine solution. For example, an initial carbon dioxide content of 12 percent might drop to 11.5 percent by the time the reservoir was nearly empty. This progressive decrease in the carbon dioxide content necessitated sampling of the gas stream during a run to determine the average composition of the gas entering the furnace. In these control analyses only the amount of carbon dioxide in the sample was determined.

\footnotetext{
i See footnote 1.
} 
Examination of the furnace after several runs showed that no soot had deposited in the silica tube used to pass the entering gases over the surface of the iron. Consequently, the composition of the gas mixture which came in contact with the liquid iron was the same as that of the gas mixture as it entered the furnace. However, the deposition of small amounts of soot on the cold parts of the furnace near the gas exit indicated that some decomposition of the carbon monoxide was taking place after it was in contact with the liquid iron. This phenomenon, and the fact that the change in composition of the gas phase, due to the reaction with liquid iron, at best was too small to be readily detected, made it useless to attempt to follow the course of the gas-liquid iron reaction by comparing the composition of the exit gases with that of the entering gases.

In the absence of a definite test to determine whether equilibrium had been reached for any particular ingot, two or more ingots were prepared with each mixture of carbon oxides. One of the ingots was prepared from a charge of high initial oxygen content, the other from a charge of low oxygen content. Equilibrium therefore was approached from both the high-oxygen and low-oxygen sides. Also, in some cases additional ingots were prepared to represent approach to equilibrium from both the high-carbon and low-carbon sides. If equilibrium were attained in the time allotted, $1 \frac{11}{2}$ to 2 hours, the carbon (or oxygen) contents of a pair of ingots should agree. However, if the carbon (or oxygen) contents of a pair of ingots do not agree, the equilibrium value should lie within the limits of the pair of experimental values. This method of determining the carbon (or oxygen) content at equilibrium with a known mixture of carbon oxides obviously is accurate only in the case where the carbon (or oxygen) contents of the pair of ingots agree. However, in case an agreement is not obtained, a reliable value for the equilibrium content can be had by averaging the two carbon (or oxygen) contents, provided the difference between the pair of ingots is small.

The base material for the charges consisted of pieces of openhearth iron cut from a one-inch round rod. The iron contained 0.07 percent oxygen, 0.003 percent alumina and 0.002 percent silica, and each piece weighed approximately 100 grams.

\section{THE SYSTEM LIQUID IRON-CARBON OXIDES}

In the first series of runs, made with gas mixtures which contained less than 10 percent carbon dioxide, gases were evolved from the metal during solidification. The evolution of gas increased in violence as the carbon-dioxide content of the mixture decreased from about 10 percent to 5 percent or less. Figure 1 shows an ingot prepared under a gas mixture containing 5 percent carbon dioxide. It was necessary to add aluminum to all charges prepared under gas mixtures containing less than 10 percent carbon dioxide in order to retain, as aluminum oxide in the solid metal, the oxygen present in the liquid metal. The amount of this aluminum oxide was determined by means of the hydrochloric-acid residue method, but segregation of the aluminum oxide complicated the problems of analysis. The results for ingots 2 and 3 in table 1 illustrate the failure to obtain duplicate results in the analyses of duplicate ingots. The average values for the carbon-oxygen products, derived from table 1, are 0.0021 for gas mixtures containing 1.5 percent carbon dioxide and 
0.0028 for 7 percent carbon dioxide. However, all of the data in table 1, including these computed carbon-oxygen products, are open to question on the grounds of the analytical difficulties which resulted from segregation of alumina.

TABLE 1.-Carbon and oxygen contents of ingots prepared in contact with carbon oxides containing less than 10 percent carbon dioxide

\begin{tabular}{|c|c|c|c|c|c|}
\hline Ingot no. & $\begin{array}{c}\mathrm{CO}_{2} \text { in } \\
\text { gas mix- } \\
\text { ture }\end{array}$ & Charge & Carbon & Oxygen & $\begin{array}{l}\text { Carbon- } \\
\text { oxygen } \\
\text { product }\end{array}$ \\
\hline & $\begin{array}{r}\text { Percent } \\
1.4 \\
1.5\end{array}$ & $\begin{array}{l}\text { Open-hearth iron melted in a vacuum } \\
\text { Open-hearth iron plus } 0.3 \text { percent graphite. }\end{array}$ & $\begin{array}{r}\text { Percent } \\
0.09 \\
.17\end{array}$ & $\begin{array}{r}\text { Percent } \\
0.016 \\
.019\end{array}$ & $\begin{array}{r}\text { Percent } \\
0.0014 \\
.0032\end{array}$ \\
\hline - & $\begin{array}{l}1.7 \\
6.9\end{array}$ & Open-hearth iron plus 0.2 percent graphite. & $\begin{array}{r}.19 \\
.05\end{array}$ & .014 & .0027 \\
\hline & 7.0 & Open-hearth iron melted in a vacuum & .04 & .077 & .0031 \\
\hline
\end{tabular}

A second series of ingots was prepared under mixtures of carbon oxides containing more than 10 percent carbon dioxide. These ingots did not evolve gas during solidification. Therefore, a determination of the carbon and oxygen contents of these ingots represents the carbon and oxygen contents of the liquid iron. Preliminary experiments with gas mixtures containing about 12 percent carbon dioxide showed that the oxygen contents of the ingots would be approximately 0.15 percent. It was necessary, therefore, to prepare charges containing more than 0.15 percent oxygen in order that the final oxygen content might be approached by a reduction in the oxygen content of the charge. These charges of high oxygen content were prepared by exposing liquid iron to a stream of carbon dioxide, ingots containing from 0.2 to 0.5 percent oxygen being obtained.

It was observed that when an ingot which contained more than 0.1 percent oxygen was melted in a magnesia crucible, the surface of the melt remained bright and clean but there was appreciable formation of slag on the surfaces of the crucible in contact with the metal, as shown in figure 2. This indicated a reaction of magnesia with iron oxide from the liquid iron. This reaction tends to decrease the oxygen content of the melt and, if it continued throughout the run, equilibrium between the liquid iron and carbon oxides might not be attained. However, the continued formation of slag throughout the run is improbable. In the high-frequency furnace, there is a sharp temperature gradient between the liquid metal and its refractory container, which results in solidification of the outer surface of the slag layer, thereby preventing further slag formation. This leads to the belief that the formation of this slag does not affect the final equilibrium content of oxygen although it does affect the rate at which equilibrium is attained.

This belief is confirmed by experiments in which beryllia crucibles were used in place of magnesia. Beryllia did not form a slag with $\mathrm{FeO}$ under the conditions of these experiments as is illustrated by the photograph of an ingot melted in a beryllia crucible (fig. 3). Ingots 10 and 11 in table 2 show the results of duplicate runs, in magnesia and beryllia crucibles. It will be shown subsequently that equilibrium probably was not attained in any of the runs in the time allowed. However, in ingot 10 the effect of the formation of the slag would be to 


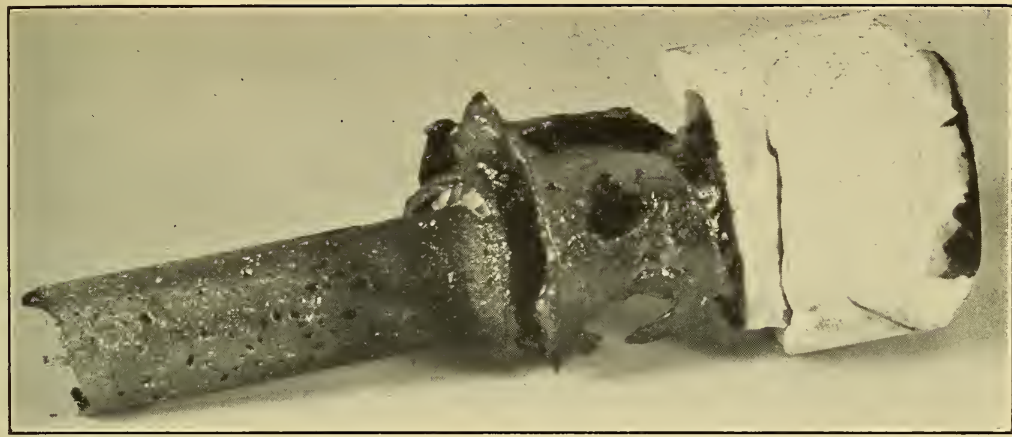

FIGURE 1.-Result of evolution of gas during solidification of molten iron prepared under a mixture of carbon oxides containing 5 percent carbon dioxide.

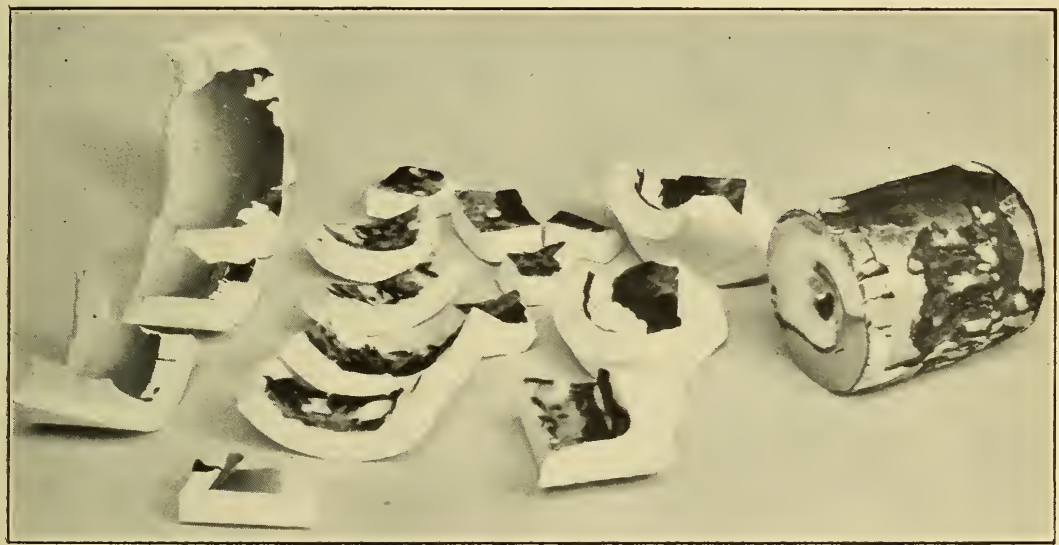

Figure 2.-Ingot prepared in a magnesia crucible.

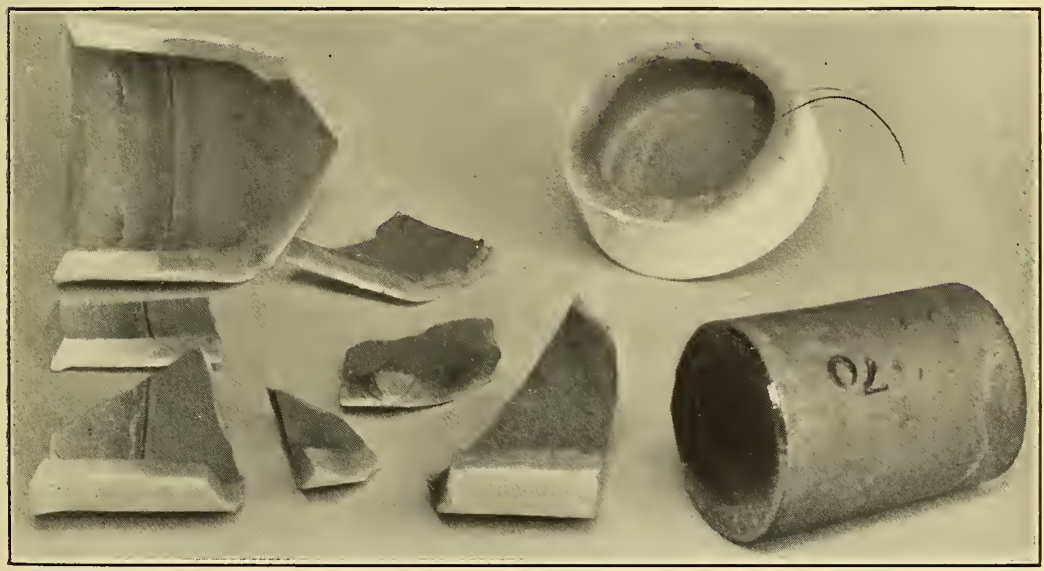

FIGURE 3.-Ingot prepared in a beryllia crucible. 
increase the rate of approach to equilibrium from the high oxygen side; hence, the oxygen content of ingot 10 should be lower, and nearer to the equilibrium value, than in the case of ingot 11 , where the oxygen content was lowered only through the action with the gas mixture. Although the two are in reasonable agreement, the oxygen content of ingot 10 actually is lower than that of ingot 11 . This is in accord with the assumption that the formation of a $\mathrm{MgO}-\mathrm{FeO}$ slag affects the rate of approach to equilibrium but does not affect the final equilibrium conditions. The oxygen content of ingots $6,7,8$, and 9 cannot be compared in regard to the formation of a $\mathrm{MgO}-\mathrm{FeO}$ slag, because each was prepared under mixtures of carbon oxides of different composition.

TABLE 2.-Carbon and oxygen contents of ingots prepared in contact with mixtures of carbon oxides containing more than 10 percent carbon dioxide

[NotE.-The letters T, C, and B refer to the top, center, and bottom portions of the ingots]

\begin{tabular}{|c|c|c|c|c|c|c|c|}
\hline $\begin{array}{l}\text { Ingot } \\
\text { no. }\end{array}$ & 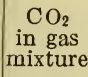 & Charge & Refractory & $\begin{array}{c}\text { Sam- } \\
\text { ple }\end{array}$ & $\begin{array}{l}\text { Car- } \\
\text { bon }\end{array}$ & $\begin{array}{l}\text { Oxy- } \\
\text { gen }\end{array}$ & $\begin{array}{l}\text { Carbon- } \\
\text { oxygen } \\
\text { product }\end{array}$ \\
\hline $6 \ldots$ & $\begin{array}{c}\text { Percent } \\
10.3 \\
\\
12.1\end{array}$ & Open-hearth iron & $\begin{array}{l}\text { Magnesia } .- \\
\text { Beryllia...- }\end{array}$ & $\left\{\begin{array}{l}\mathrm{T} \\
\mathrm{C} \\
\mathrm{B} \\
\mathrm{T} \\
\mathrm{C}\end{array}\right.$ & $\begin{array}{r}\text { Percent } \\
0.016 \\
.018 \\
.026 \\
.018 \\
.014\end{array}$ & $\begin{array}{c}\text { Percent } \\
0.107 \\
.104 \\
.111 \\
.127 \\
.131\end{array}$ & $\begin{array}{r}0.0021 \\
.0021\end{array}$ \\
\hline $\begin{array}{l}8 .- \\
9--\end{array}$ & $\begin{array}{l}14.3 \\
16.7\end{array}$ & $\begin{array}{l}\text { Open-hearth iron fused in a vacuum } \\
\text { - }\end{array}$ & Magnesia & B & $\begin{array}{r}.019 \\
-\end{array}$ & $\begin{array}{l}.117 \\
.168 \\
.174\end{array}$ & 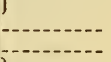 \\
\hline $10_{-}$ & 11.3 & Oxidized open-hearth iron.-. & & $\begin{array}{l}1 \\
\mathrm{C} \\
\mathrm{B}\end{array}$ & $\begin{array}{l}.021 \\
.018 \\
.018\end{array}$ & $\begin{array}{l}.139 \\
.137 \\
.138\end{array}$ & .0026 \\
\hline $11 \ldots$ & 11.2 & _.._do_... & Beryllia_- & $\stackrel{\mathrm{C}}{\mathrm{C}}$ & $\begin{array}{l}.017 \\
.022\end{array}$ & .151 & .0029 \\
\hline
\end{tabular}

The results for the series of ingots prepared under gas mixtures which contained more than 10 percent carbon dioxide are shown in table 2. In order to obtain reliable values for the carbon and oxygen contents of ingots of this series, each ingot was cut laterally into three discs. Half of each disc was used for a carbon determination and the remaining half for an oxygen determination by the vacuum fusion method. In computing the carbon-oxygen product for an ingot the averages of the three carbon and of the three oxygen determinations were used. Ingots $6,7,10$, and 11 were prepared under approximately the same gas compositions. Ingots 6 and 7 were prepared from charges containing a low initial oxygen content, whereas ingots 10 and 11 were obtained from charges with high initial oxygen contents. Ingot 10 is believed to approach equilibrium more nearly than does ingot 11, for reasons already discussed. The carbon-oxygen product obtained for molten iron under mixtures of carbon oxides containing approximately 11 percent carbon dioxide therefore is 0.0023 . This value is obtained by taking the numerical average of the products for ingots 6 or 7 and 10. The value 0.0023 is in good agreement with the value 0.0025 obtained in previous work. ${ }^{5}$ It is also in qualitative agreement with the results shown in table 1. It is evident that a value of the order of magnitude of 0.0025 , for the carbon-oxygen product in liquid iron at about $1,600^{\circ} \mathrm{C}$. and one atmosphere pressure, is a reproducible value. The accuracy of this

${ }^{6}$ See footnote 1. 
value will be demonstrated in the subsequen $t$ discussion of the results obtained for the system liquid iron-hydrogen-water vapor.

\section{THE SYSTEM LIQUID IRON-HYDROGEN-WATER VAPOR}

The same general procedure that was employed in the experiments with carbon oxides was used in preparing a few ingots under hydrogen which contained approximately 4 percent water vapor. The hydrogen-water vapor mixture was made by passing a stream of purified hydrogen through a saturated sodium chloride solution. The saturated brine solution was used in order that the partial pressure of water vapor in the hydrogen-water vapor mixture would be less than the vapor pressure of water at room temperature. This prevented water from forming in the tubing that led the gases to the furnace. The hydrogen-water vapor mixture was passed through the furnace at a rate of $150 \mathrm{ml}$ per minute for a period of from $1 \frac{1 / 2}{2}$ to 2 hours.

In two runs the original charge consisted of pieces of open hearth iron which contained 0.07 percent oxygen. In these two runs therefore, equilibrium in the metal was approached from the high oxygen side. In two additional runs equilibrium was approached from the low oxygen side through the use of charges of open hearth iron which had been held molten under a stream of hydrogen for one half hour. Previous experiments had shown that this treatment reduced the oxygen content to about 0.005 percent. At the start of each experimental run the charge was melted in vacuo. This resulted in almost complete elimination of the small amount of carbon present in the ingot iron, accompanied by a slight reduction in oxygen. It was assumed that the carbon content of the charges after this treatment was too low to exert any effect on the iron-hydrogen-oxygen equilibrium. These charges after the $1 \frac{11}{2}$ to 2 -hour exposure to the hydrogen-water vapor mixture at $1,580^{\circ} \mathrm{C}$. did not evolve gas during solidification. However, several attempts to prepare ingots at $1,620^{\circ} \mathrm{C}$. did result in the evolution of a small amount of gas during solidification.

TABLE 3.-Oxygen and hydrogen contents of ingots prepared in contact with mixtures of hydrogen and water

[NoTE.- The letters $\mathrm{T}$ and B refer to the top and bottom portions of the ingots]

\begin{tabular}{|c|c|c|c|c|c|}
\hline Ingot no. & $\begin{array}{l}\text { Water } \\
\text { vapor } \\
\text { in gas } \\
\text { mixture }\end{array}$ & Charge & $\begin{array}{c}\text { Sam- } \\
\text { ple }\end{array}$ & Oxygen & $\begin{array}{c}\text { Hydro- } \\
\text { gen }\end{array}$ \\
\hline $12 \ldots$ & $\begin{array}{r}\text { Percent } \\
3.9\end{array}$ & $\begin{array}{l}\text { Open hearth iron fused and kept in contact with a stream } \\
\text { of } \mathrm{H}_{2} \text { for } 1 / 2 \text { hour }\end{array}$ & $\left\{\begin{array}{l}\mathrm{T} \\
\mathrm{B}\end{array}\right.$ & $\begin{array}{r}\text { Percent } \\
0.011 \\
.008\end{array}$ & $\begin{array}{r}\text { Percent } \\
0.0003 \\
.0003\end{array}$ \\
\hline 13 & 4.2 & Open hearth iron & & .013 & .0001 \\
\hline 14 & 4.3 & Same as no. 12. & & .011 & .0001 \\
\hline 15 & 3.4 & Same as no. 13. & & $\begin{array}{l}.011 \\
.009\end{array}$ & .0001 \\
\hline
\end{tabular}

The results of the analyses of the ingots prepared under hydrogenwater vapor at $1,580^{\circ} \mathrm{C}$. are shown in table 3 . Top and bottom samples of each ingot were analysed for oxygen. The results show the absence of serious segregation. 


\section{DISCUSSION}

In previous work on the system liquid iron-carbon oxides the data obtained have been open to question for two reasons: First, uncertainty on account of experimental difficulties; second, uncertainty whether or not the data represented equilibrium. The first uncertainty has to do with the reproducibility of the data under the conditions of the experiment, the second with the accuracy of the data, at least in regard to the order of magnitude.

The present data have yielded an average carbon-oxygen product of 0.0023 for liquid iron at about $1,600^{\circ} \mathrm{C}$. and under one atmosphere of carbon oxides. A value of 0.0025 was obtained under similar conditions in previous work. These values were obtained from ingots which were prepared from charges of high and low oxygen contents and from high and low carbon contents and under mixtures of carbon oxides of various compositions. Therefore, it is concluded that the values, 0.0023 and 0.0025 , can be reproduced.

The accuracy of any data representing an equilibrium is established when the data can be shown to be in agreement with other equilibria. In the following discussion it will be shown that the data in tables 2 and 3 are in good agreement with accepted data for the well-known water-gas reaction and that the data in table 2 are in qualitative agreement with accepted data on the $\mathrm{Fe}-\mathrm{C}$ system.

The first equilibrium constant to be derived is the constant for the reduction of iron oxide by carbon monoxide according to equation (1).

$$
\begin{gathered}
\mathrm{FeO} \text { (in solution) }+\mathrm{CO} \text { (gas) }=\mathrm{Fe} \text { (liq.) }+\mathrm{CO}_{2} \text { (gas); } \\
K_{1}=\frac{N_{\mathrm{Fe}}}{N_{\mathrm{FeO}}} \cdot \frac{p_{\mathrm{CO}_{2}}}{p_{\mathrm{CO}}}
\end{gathered}
$$

The computation of this constant and subsequent constants from the data in table 2 necessitates the assumption that the free iron in the liquid iron solution at these carbon contents is essentially equal to 1 minus $N_{\mathrm{FeO}}$ minus $N_{\mathrm{Fe}_{3} \mathrm{C}}$, where $N$ is the mol fraction. The assumption is based on the following considerations: (a) the presence of appreciable amounts of carbon monoxide and carbon dioxide in liquid iron is improbable; ${ }^{6}$ (b) the oxygen content of liquid iron can be considered as equivalent to ferrous oxide, since it has been shown that the ratio of iron oxide in a lime slag to the oxygen content of liquid iron is a constant; ${ }^{7}$ (c) the carbon in liquid iron is present as iron carbide that dissociates slightly at high carbon contents according to the reaction $\mathrm{Fe}_{3} \mathrm{C}=\mathrm{C}+3 \mathrm{Fe} .^{8}$

The data for the computation of $K_{1}$ are shown in table 4 . In computing the mol fractions the average values for the carbon and oxygen contents of each ingot listed in table 2 have been used. The first four values for $K_{1}$ are computed from the results of runs in which equilibrium was approached from the low oxygen side. If equilibrium were not attained, the final oxygen content would be lower

\footnotetext{
${ }_{6}^{6}$ V. H. Gottschalk and R. S. Dean, The Solubility of Gases in Metals. A.I.M.M.E. Preprint, February 1932, 16 pages.

7 C. H. Herty, Jr., et al., The Physical Chemistry of Steel-making. The Solubility of Iron Oxide in Iron. Min. \& Met. Invest. Bull. 34, U.S. Bureau of Mines, Carnegie Inst. of Tech. and Mining \& Met. Advisory Boards (1927).

8 Friedrick Körber and Willy Oelsen, Thermodynamic Considerations of Several Equilibrium Curves of the System Iron-Carbon. (Thermodynamisches Betrachtungen Zu einigen Gleichgewichtskurven des Zustandsschaubildes Eisen-Kohlenstofi). Archiv. für das Eisenhüttenwesen, vol, 5. pp. 569-578, May 1932. Extended abstract by J, B. Austin, Metals and Alloys, vol. 4, pp. 49-53; April 1933.
} 
than the equilibrium concentration and the value for the constant $K_{1}$ would be higher than the correct value. On the other hand, in runs 5 and 6 equilibrium was approached from the high oxygen side. If equilibrium were not attained in these two runs, the final oxygen content would be higher than the equilibrium concentration and the value for $K_{1}$ would be correspondingly low. The calculated values for $K_{1}$ in table 4 indicate that equilibrium was not fully attained in the time allowed. Consequently, the true value for $K_{1}$ is considered to lie between the lowest value obtained in the first four runs, 28.2, and the highest value obtained in the last two runs, 26.2. The numerical average of these two values, 27.0 , was used in subsequent computations as the value of $K_{1}$ at $1580^{\circ} \mathrm{C}$.

TABLE 4.-Computation of equilibrium constants $K_{1}$ and $K_{4}$

\begin{tabular}{|c|c|c|c|c|c|c|c|c|c|c|c|}
\hline Ingot no. & $\mathrm{NFe}_{3} \mathrm{C}$ & $N_{\text {FeO }}$ & $N_{\mathrm{Fe}}$ & $\begin{array}{l}p_{\mathrm{CO}_{2}} \\
\text { atm. }\end{array}$ & $\begin{array}{c}p_{\mathrm{Co}} \\
\mathrm{atm}\end{array}$ & $\begin{array}{l}N_{\mathrm{Fe}} / \\
N_{\mathrm{FeO}}\end{array}$ & $\begin{array}{c}p_{\mathrm{CO}_{2}} l \\
p_{\mathrm{CO}}\end{array}$ & $K_{1}$ & $\begin{array}{l}N^{3} \mathrm{Fe} / \\
N_{\mathrm{Fe}_{3} \mathrm{C}}\end{array}$ & $\begin{array}{l}p^{2} \mathrm{Co} / \\
p_{\mathrm{CO}_{2}}\end{array}$ & $K_{4}$ \\
\hline 10 & $\begin{array}{r}0.00094 \\
.00079 \\
.00089 \\
.00089\end{array}$ & $\begin{array}{r}0.00374 \\
.00444 \\
.00588 \\
.00609 \\
.00483 \\
.00543\end{array}$ & $\begin{array}{r}0.995 \\
.995 \\
.993 \\
.993 \\
.994 \\
.994\end{array}$ & $\begin{array}{r}0.103 \\
.121 \\
.143 \\
.167 \\
.113 \\
.112\end{array}$ & $\begin{array}{r}0.897 \\
.879 \\
.857 \\
.833 \\
.887 \\
.888\end{array}$ & $\begin{array}{l}266 \\
224 \\
169 \\
163 \\
206 \\
183\end{array}$ & $\begin{array}{l}0.115 \\
.138 \\
.167 \\
.200 \\
.127 \\
.126\end{array}$ & $\begin{array}{l}30.6 \\
29.9 \\
28.2 \\
32.6 \\
26.2 \\
23.1\end{array}$ & $\begin{array}{r}1052 \\
1247 \\
1110 \\
1110\end{array}$ & $\begin{array}{l}7.81 \\
6.39\end{array}$ & \begin{tabular}{r}
8220 \\
7970 \\
\hdashline 7 \\
7830 \\
- \\
\end{tabular} \\
\hline
\end{tabular}

$\mathrm{K}_{1}$ average of 8 and 10

The constant $K_{1}$ can be combined with the data for the liquid ironhydrogen-water vapor system, listed in table 3 , to yield a constant for the familiar water-gas reaction. Equilibrium in the iron-hydrogen-water vapor system is represented by equation (2)

$\mathrm{FeO}$ (in solution) $+\mathrm{H}_{2}$ (gas) $\rightleftarrows \mathrm{Fe}$ (liq.) $+\mathrm{H}_{2} \mathrm{O}$ (gas); $K_{2}=\frac{N_{\mathrm{Fe}}}{N_{\mathrm{FeO}}}$.

$$
\frac{p_{\mathrm{H}_{2} \mathrm{O}}}{p_{\mathrm{H}_{2}}}
$$

and $K_{2}$ divided by $K_{1}$ is equal to $K_{3}$, the constant for the water gas reaction (3).

$$
\mathrm{CO}_{2} \text { (gas) }+\mathrm{H}_{2} \text { (gas) } \rightleftarrows \mathrm{CO} \text { (gas) }+\mathrm{H}_{2} \mathrm{O} \text { (gas) } ; K_{3}=\frac{p_{\mathrm{CO}}}{p_{\mathrm{CO}_{2}}} \cdot \frac{p_{\mathrm{H}_{2} \mathrm{O}}}{p_{\mathrm{H}_{2}}}=\frac{K_{2}}{K_{1}}
$$

\begin{tabular}{|c|c|c|c|c|c|c|c|}
\hline Ingot no. & $N_{\mathrm{FeO}}$ & $N_{\mathrm{Fe}}$ & $\begin{array}{l}p_{\mathrm{H}_{2} \mathrm{O}} \\
\text { atm. }\end{array}$ & $\begin{array}{c}p_{\mathrm{H}_{2}} \\
\text { atm. }\end{array}$ & $N_{\mathrm{Fe}} / N_{\mathrm{FeO}}$ & $p_{\mathrm{H}_{2} \mathrm{O}} / p_{\mathrm{H}_{2}}$ & $K_{2}$ \\
\hline 12 & $\begin{array}{r}0.000350 \\
.000381 \\
.000420 \\
.000350\end{array}$ & $\begin{array}{r}0.999 \\
.999 \\
.999 \\
.999\end{array}$ & $\begin{array}{r}0.039 \\
.042 \\
.043 \\
.034\end{array}$ & $\begin{array}{r}0.961 \\
.958 \\
.957 \\
.966\end{array}$ & $\begin{array}{l}2854 \\
2622 \\
2379 \\
2854\end{array}$ & $\begin{array}{r}0.0406 \\
.0438 \\
.0449 \\
.0352\end{array}$ & $\begin{array}{l}116 \\
115 \\
107 \\
101\end{array}$ \\
\hline
\end{tabular}

TABLE 5.-Computation of equilibrium constant $K_{\varkappa}$.

The computed values for $K_{2}$, in table 5 , average 110 for four ingots; the value for $K_{1}$ in table 4 is 27.0 ; the value derived for $K_{3}$, therefore, is 4.07 . The value for the water-gas constant at $1,580^{\circ} \mathrm{C}$. is $3.95 \mathrm{com}-$ puted with the aid of Chipman's free energy equation. ${ }^{9}$ The value for $K_{3}$ derived from the present work and from the free energy equa-

\footnotetext{
'J. Chipman, The Free Energy of Water, Carbon Monoxide, Carbon Dioxide, and Methane, Ind. \& Eng. Chem., vol. 24, pp. 1013, 1932 .
} 
tion are considered to be in close enough agreement to demonstrate that the data in tables 2 and 3 agree with accepted data for the watergas reaction.

The second constant to be derived from the data in table 2 is the constant for the oxidation of iron carbide by carbon dioxide according to equation (4).

$\mathrm{Fe}_{3} \mathrm{C}$ (in solution) $+\mathrm{CO}_{2}$ (gas) $\leftrightarrows 3 \mathrm{Fe}$ (liq.) $+2 \mathrm{CO}$ (gas); $\mathrm{K}_{4}$

$$
=\frac{N^{3} \mathrm{Fe}}{N_{\mathrm{Fe}_{3} \mathrm{C}}} \cdot \frac{p^{2} \mathrm{CO}}{p_{\mathrm{CO}_{2}}}
$$

The average value obtained for $K_{4}$ is $7.9 \times 10^{3}$ according to the computations indicated in table 4.

If the relation between the carbon content of liquid iron and the partial pressures of carbon oxides as expressed by $K_{4}$ is true over the complete range of possible carbon contents, then the carbon content can be determined from a knowledge of the composition of a mixture of carbon oxides at one atmosphere pressure. The composition of carbon oxides at one atmosphere pressure in equilibrium with graphite can be obtained from the equilibrium constant of the producer-gas reaction (5).

$$
\mathrm{C} \text { (graphite) }+\mathrm{CO}_{2} \text { (gas) } 52 \mathrm{CO} \text { (gas); } K_{5}=\frac{p_{\mathrm{CO}}^{2}}{p_{\mathrm{CO}_{2}}}
$$

Inasmuch as the mixture of carbon oxides at one atmosphere pressure in equilibrium with graphite is also in equilibrium with liquid iron saturated with graphite, $K_{5}$ can be combined with $K_{4}$ to give the value of $\frac{N^{3} \mathrm{Fe}}{N_{\mathrm{Fe}_{3} \mathrm{C}}}$. The value of $K_{5}$ at $1,580^{\circ} \mathrm{C}$. is $14.4 \times 10^{3}$ when computed with the aid of Chipman's free energy equation ${ }^{10}$ for the producer-gas reaction. The value of $N_{\mathrm{Fe}} / N_{\mathrm{Fe}_{3} \mathrm{C}}$ when liquid iron is saturated with graphite therefore, is 0.55 . The carbon content of liquid iron then can be computed from the value 0.55 by considering $N_{\mathrm{Fe}}$ equal to $1-N_{\mathrm{Fe}_{3} \mathrm{C}}$. The value of $N_{\mathrm{Feo}}$ is negligible at high carbon contents. On this basis the carbon content corresponding to 0.55 is 4.4 percent. The carbon content of liquid iron saturated with graphite is 5.3 percent according to the iron-carbon diagram. ${ }^{11}$ It is concluded therefore that $K_{4}$, is not applicable over the complete range of possible carbon contents. In order to correlate the data describing liquid iron saturated with graphite and the data in table 4 it must be assumed that iron carbide dissociates to some extent, according to equation (6).

$\mathrm{Fe}_{3} \mathrm{C}$ (in solution) $\rightleftharpoons 3 \mathrm{Fe}$ (liq.) $+\mathrm{C}$ (in solution); $\mathrm{K}_{6}=\frac{N^{3} \mathrm{Fe}}{N_{\mathrm{Fe}_{3} \mathrm{C}}} \cdot \mathrm{N}_{\mathrm{C}}$

$K_{6}$ can be computed from the value of $N^{3} \mathrm{Fe} / N_{\mathrm{Fe}_{3} \mathrm{C}}, 0.55$ and the carbon content, 5.3, when liquid iron is saturated with graphite. This computed value for $K_{6}, 0.038$, can be used with $K_{1}$ and $K_{4}$ to derive the data for the dissociation of $\mathrm{Fe}_{3} \mathrm{C}$, at different carbon contents, recorded in table 6. It is evident that the dissociation of $\mathrm{Fe}_{3} \mathrm{C}$ is negligible at very low carbon contents but becomes increasingly important as carbon contents of about 5 percent are reached.

\footnotetext{
10 See footnote 9.

11 See footnote 8 .
} 
TABLE 6.-The carbon and oxygen contents of liquid iron in equilibrium with different mixtures of carbon oxides at one atmosphere pressure and $1,580^{\circ} \mathrm{C}$ computed from $K_{1}, K_{4}$, and $K_{6}$

\begin{tabular}{|c|c|c|c|c|c|c|}
\hline $\begin{array}{l}\text { Carbon } \\
\text { dioxide }\end{array}$ & $\begin{array}{c}\text { Carbon } \\
\left.\text { (as } \mathrm{Fe}_{3} \mathrm{C}\right)\end{array}$ & $\begin{array}{l}\text { Carbon } \\
\text { (as C) }\end{array}$ & $\begin{array}{l}\text { Total } \\
\text { carbon }\end{array}$ & Oxygen & $\begin{array}{c}\text { Carbon- } \\
\text { oxygen } \\
\text { product } \\
\text { (C) } x(0)\end{array}$ & $\begin{array}{l}\text { Phases present in } \\
\text { addition to gas and } \\
\text { liquid iron phases }\end{array}$ \\
\hline Percent & Percent & Percent & \multirow{8}{*}{$\begin{array}{c}\text { Percent } \\
0.008 \\
.023 \\
.041 \\
.131 \\
.259 \\
.493 \\
1.742 \\
2.589 \\
5.3^{b}\end{array}$} & \multirow{8}{*}{$\begin{array}{l}\text { Percent } \\
0.28 \text { a } \\
.117 \\
.068 \\
.0216 \\
.0105 \\
.0049 \\
.00067 \\
.00029 \\
.000025\end{array}$} & \multirow{8}{*}{$\begin{array}{c}\text { Percent } \\
0.0022 \\
.0027 \\
.0028 \\
.0028 \\
.0027 \\
.0024 \\
.0012 \\
.0007 \\
.0001\end{array}$} & \multirow{8}{*}{ FeO (slag). } \\
\hline $\begin{array}{l}21.1 \\
10.0\end{array}$ & $\begin{array}{l}0.008 \\
.022\end{array}$ & 0.00084 & & & & \\
\hline & .039 & $\begin{array}{l}.0015 \\
.0015\end{array}$ & & & & \\
\hline 2.0 & .126 & .0049 & & & & \\
\hline 1.0 & 249 & .0098 & & & & \\
\hline 0.5 & $\begin{array}{r}.474 \\
1.656\end{array}$ & $\begin{array}{l}.0194 \\
.0856\end{array}$ & & & & \\
\hline .05 & 2. 434 & .1553 & & & & \\
\hline .0 & 44 & & & & & \\
\hline
\end{tabular}

a Oxygen content of liquid iron in equilibrium with iron oxide. See footnote 7.

$b$ Carbon content of liquid iron in equilibrium with graphite. See footnote 8.

Körber and Oelson ${ }^{13}$ showed that the latent heat of fusion of pure iron can be correlated with the carbon content of the solidus and liquidus of the iron carbon diagram if it is assumed that the carbon content of the liquidus consists of $\mathrm{Fe}_{3} \mathrm{C}$ slightly dissociated. In the preceding discussion it has been shown that the carbon contents of liquid iron and the corresponding composition of carbon oxides at one atmosphere pressure can be correlated if it is assumed that the carbon content of liquid iron consists of $\mathrm{Fe}_{3} \mathrm{C}$ slightly dissociated. The two sets of data therefore lead to the same assumption and consequently can be concluded to be in qualitative agreement. A more quantitative comparison could be made if $K_{6}$ could be computed as a function of temperature from the iron-carbon diagram and the latent heat of fusion of pure iron, but the available data are not sufficiently reliable and the computations are too sensitive to errors in the data.

The constants, $K_{1}, K_{4}$, and $K_{6}$, have been used further to compute the variations in the carbon-oxygen product with varying composition of the carbon-oxides mixture at one atmosphere pressure for liquid iron at $1,580^{\circ} \mathrm{C}$. These computations, recorded in table 6, show that the carbon-oxygen product is not a constant for all mixtures of carbon dioxide and carbon monoxide. Experimental work is practicable only with material which contains between 0.01 and 0.5 percent carbon and between 0.005 and 0.3 percent oxygen. It is evident that within these limits the carbon-oxygen product lies between 0.002 and 0.003 . The average value of 0.0025 can be used throughout the range which can be investigated experimentally, since the error resulting from the use of this single value will be well within the limits of precision of the experimental procedure.

\section{SUMMARY}

The present data on the system liquid iron-carbon oxides have been used in computing the equilibrium constants of the following equations $\mathrm{FeO}$ (in solution) $+\mathrm{CO}$ (gas) $\rightleftarrows \mathrm{Fe}$ (liq.) $+\mathrm{CO}_{2}$ (gas);

$$
K_{1}=\frac{N_{\mathrm{Fe}}}{N_{\mathrm{FeO}}} \cdot \frac{p_{\mathrm{CO}_{2}}}{p_{\mathrm{CO}}}
$$

${ }^{13}$ See footnote 8. 
$\mathrm{Fe}_{3} \mathrm{C}$ (in solution) $+\mathrm{CO}_{2}$ (gas) $\rightleftarrows 3 \mathrm{Fe}$ (liq.) $+2 \mathrm{CO}$ (gas);

$$
K_{4}=\frac{N^{3} \mathrm{Fe}}{N_{\mathrm{Fe}_{3} \mathrm{C}}} \cdot \frac{p^{2} \mathrm{CO}}{p_{\mathrm{CO}_{2}}}
$$

$\mathrm{Fe}_{3} \mathrm{C}$ (in solution) $\rightleftarrows \mathrm{Fe}$ (liq.) $+\mathrm{C}$ (in solution) $; K_{6}=\frac{N^{3}{ }_{\mathrm{Fe}}}{N_{\mathrm{Fe}_{3} \mathrm{C}}} \cdot N_{\mathrm{C}}$

The computed values of $K_{1}, K_{4}$ and $K_{6}$ at $1580^{\circ} \mathrm{C}$. are $27.0,7.9 \times 10^{3}$ and 0.038 respectively. The values $K_{1}$ and $K_{4}$ are reproducible at one atmosphere pressure and $1580^{\circ} \mathrm{C}$, and can be obtained by approaching equilibrium from high and low carbon contents and from high and low oxygen contents for several compositions of carbon oxides.

Data on the system liquid iron-hydrogen-water vapor have been used to compute the equilibrium constant of the following equation $\mathrm{FeO}$ (in solution) $+\mathrm{H}_{2}$ (gas) $\rightleftarrows \mathrm{Fe}$ (liq) $+\mathrm{H}_{2} \mathrm{O}$ (gas);

$$
K_{2}=\frac{N_{\mathrm{Fe}}}{N_{\mathrm{FeO}}} \cdot \frac{p_{\mathrm{H}_{2} \mathrm{O}}}{p_{\mathrm{H}_{2}}}
$$

The value of $K_{2}$ at $1580^{\circ} \mathrm{C}$. is 110 . This value is reproducible and can be obtained by approaching equilibrium from high and low oxygen contents.

The accuracy of the values of $K_{1}$ and $K_{2}$ is established because, when combined as a ratio $K_{2} / K_{1}$, they give a value, 4.07 , that is in good agreement with the value, 3.95 , for the equilibrium constant of the water-gas reaction. Computations based on the value for the constant $K_{4}$ indicate that the carbon content in liquid iron consists of $\mathrm{Fe}_{3} \mathrm{C}$ slightly dissociated. This conclusion likewise can be derived from thermodynamic considerations of the iron-carbon diagram. This qualitative agreement with the approved data of the iron-carbon diagram indicates that the value for $K_{4}$ is at least of the correct order of magnitude.

The value 0.0025 previously obtained for the carbon-oyxgen product, in liquid iron, at $1600^{\circ} \mathrm{C}$. and in contact with mixed carbon oxides at one atmosphere pressure, has been confirmed. Additional experiments have permitted the correlation of the carbon oxides data with the data for the familiar water gas and producer gas reactions. The accuracy of the carbon oxides data, and of the corresponding carbon-oxygen product, 0.0025 , is therefore established. This value can be used without appreciable error for carbon and oxygen contents within the limits of 0.01 to 0.5 percent carbon and 0.005 to 0.3 percent oxygen.

Washington, July 29, 1933. 